\title{
Measurements in Sensor Network based Oil Monitoring Control
}

\author{
Manisha \\ M.tech Scholar (CSE) Department, \\ Regional Institute of Engg. and Tech (RIMT), \\ Mandi Gobindgarh, Punjab, India
}

\author{
Farminder Singh \\ Asst. Professor in CSE Department, \\ Regional Institute of Engg. and Tech (RIMT), \\ Mandi Gobindgarh, Punjab, India
}

\begin{abstract}
Wireless Networks gained great attention in recent years. In this paper, the proposed Sensor Network Based Oil monitoring system a demo design is proposed. Our system takes the measurements of fluid levels by installed sensors in fluid storing tank. This system works with the 3 oil tanks (tank A, B, C) having same types of sensors stored in tanks to sense the data (level of oil). All three information regarding three levels will be send via RF transmitter. Sent out signals will be received by $\mathrm{RF}$ receiver that will be connected to other processor via RF decoder at recording and display end. This is system, which will be connected to computer system's serially via RS-232 interface to send the measured data or information into computer system to display measurement in form of bars and to record measured data in computer's database. The Aim of this study is to illustrate how much accurate the level of oil in particular tank during different Temperature conditions and how much variations will be there in the measurements at that time.
\end{abstract}

\section{Keywords}

Wireless Network, Intelligent System, Fuzzy Logic, Artificial neural networks, Radio Module, Wireless Communication.

\section{INTRODUCTION}

Method behind the system is to take the measurements of fluid levels by installed sensors in fluid storing tank. When fluid level touches the sensors, an appropriate electrical signal will be send to processor installed on remote site. This processor will decide what to do now. It will trigger RF encoder to modulate this signal and will transmit information via RF transmitter. Likewise, there will be three sensors installed in tanks to make it three tier sensing mechanism. All three information regarding three levels will be sent in same way as stated above. Sent out signals will be received by RF receiver that will be connected to other processor via RF decoder at recording and display end. This is system, which will be connected to computer system's serial via RS-232 interface to send the measured data or information into computer system to display measurement in form of bars and to record measured data in computer's database.

These signals are brought to processor connected outside the computer via RS-232, and will be transmitted to remote site controlling circuits via Radio encoders and RF transmitters.

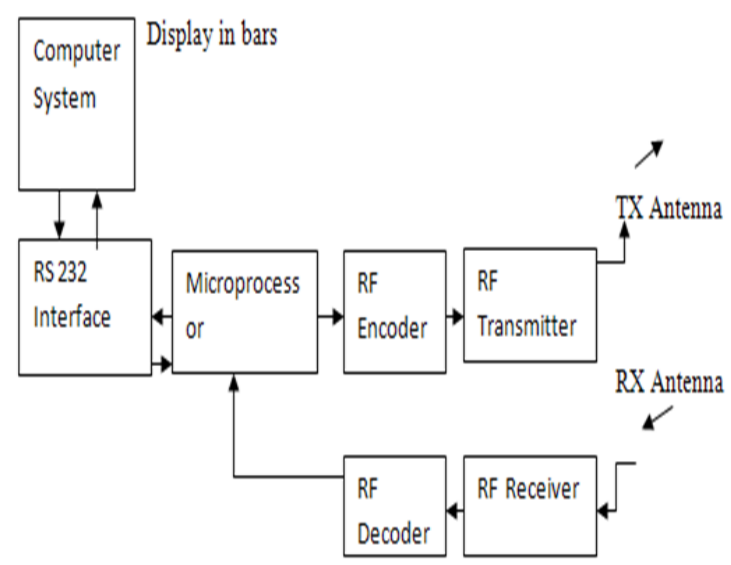

Figure 1: Block Diagram Of the System

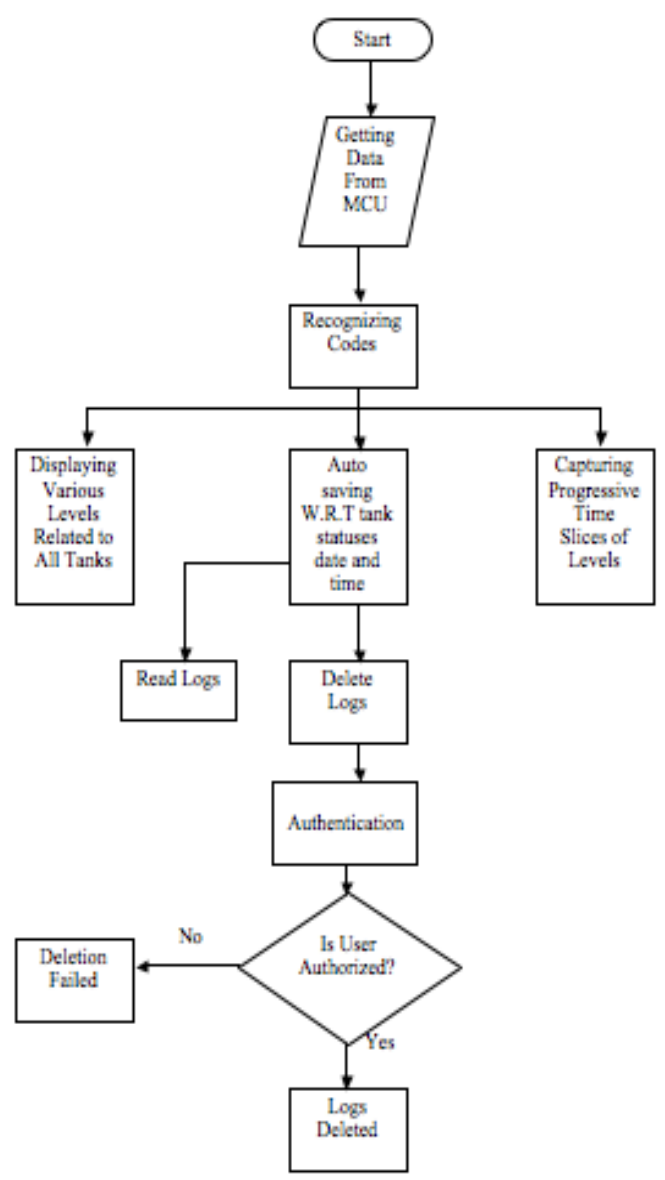

Figure 2: Data Flow Diagram of the System 


\section{SYSTEM DESCRIPTION}

System is having three sections:

1) Transmitter Section

2) Receiver Section

3) Software Designed

1) Transmitter Section: Transmitter Section is designed with One Step-Down Transformer which convert AC voltage to DC voltage and then current passed out through diodes which allow the current to pass in one direction and after that there is a voltage regulator which gives the voltage to the system according to the requirement and then there is a capacitor which filter out the voltage and then voltage goes to the RF Encoder and RF Encoder Activates, RF Encoder starts receiving sensed data from the Microcontroller which is further attached to the RF Encoder, Microcontroller receive the sensed data from the connected three oil level sensing units made up of 9 transistors and 27 resistors.

This system captures a reading of 3 oil tanks up to 3 levels via transistorized NPN sensors whose probes are dipped into oil. It contains PU (processing unit) next to the sensors which processes a measured data accepted from sensors via inputoutput port and then makes codes which defines a particular tank with particular level at receiving end. The signal containing codes are then spotted by RF receiver which hands over the signal to decoder. RF decoder here uses PCM approach to decode the signals into digital form for further processing. It transforms the signals into 4-bit digital data codes and put them into PU. PU recognized these codes one at a time that to which tank that it belongs and for which level that it speak.

Transmitting Site: -

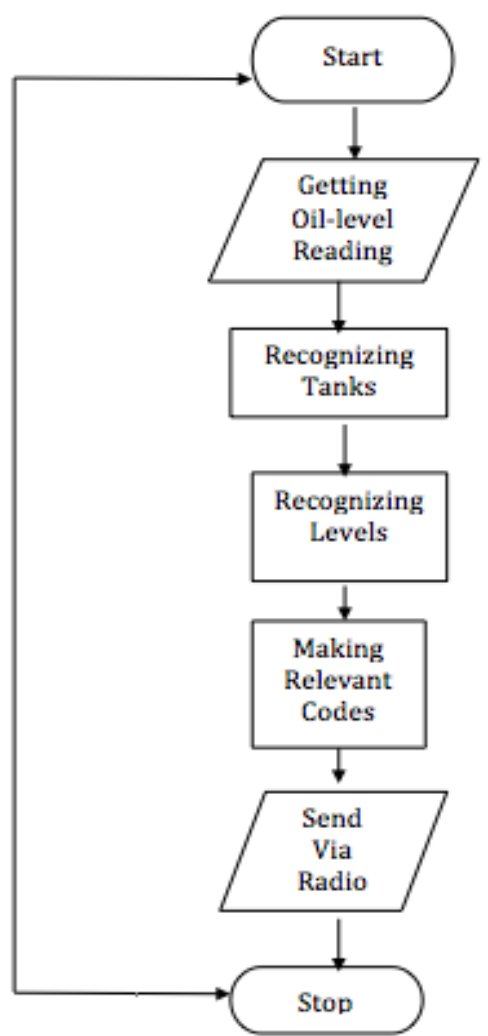

Figure 3: Working of Transmitter Site
2) Receiver Section: This Section is designed with one step down Transformer which convert AC to DC voltage and then there is a voltage regulator which provides the required voltage to the system after that voltage goes to the microcontroller and then microcontroller starts receiving sensed data information one by one from RF Decoder which receives data from the RF encoder sending site in the form of 4-bit data. In this section microcontroller send the received information to the MAX-232 chip to transfer sensed information to the software via RS-232 serial port interface and then the data further transfers to the display screen for showing the results.

\section{Receiving Site:}

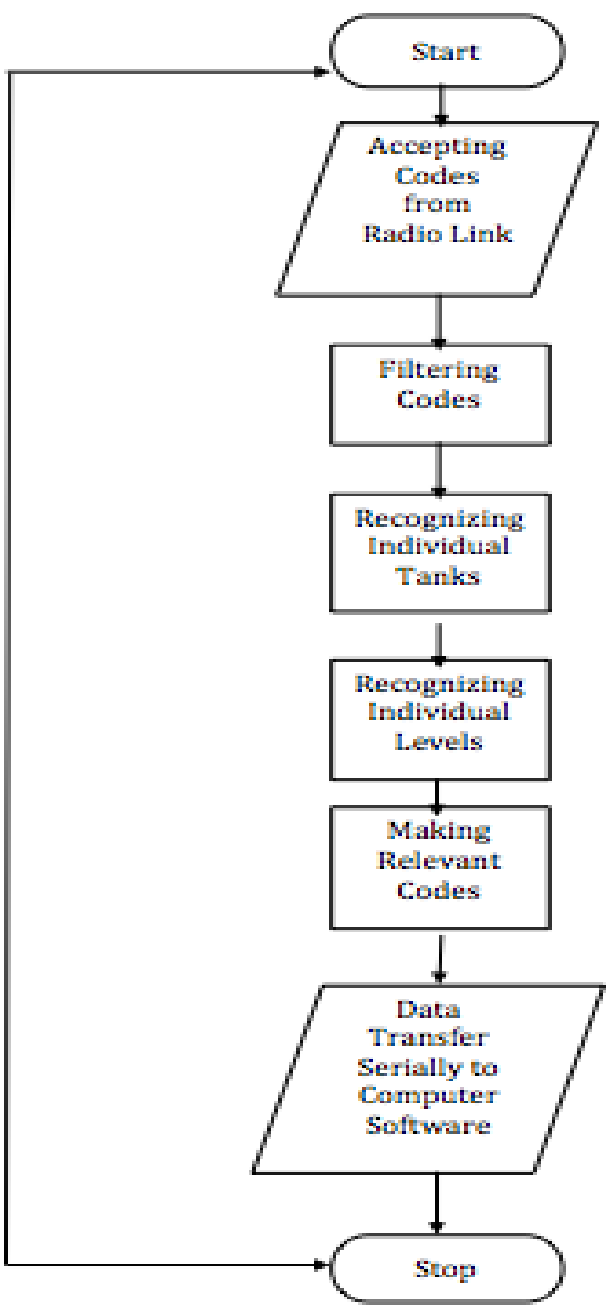

Figure 4: Working of Receiving Site

3) Software Designed: In This Section the data which is received, decoded and processed by receiving unit will be displayed in the form of levels in computer system on the software. This software is created with the help of Visual Basic. This software has 3 progress bars one for each oil tank and all progress bars have 3- levels (low, half and full) on which software firstly gets data about tank and level from processor placed outside via serial port (RS-232 interface) and displays progress bars with level and percentage of filling tank. Also it contains a space to save a data on file maintained on hard disk. 


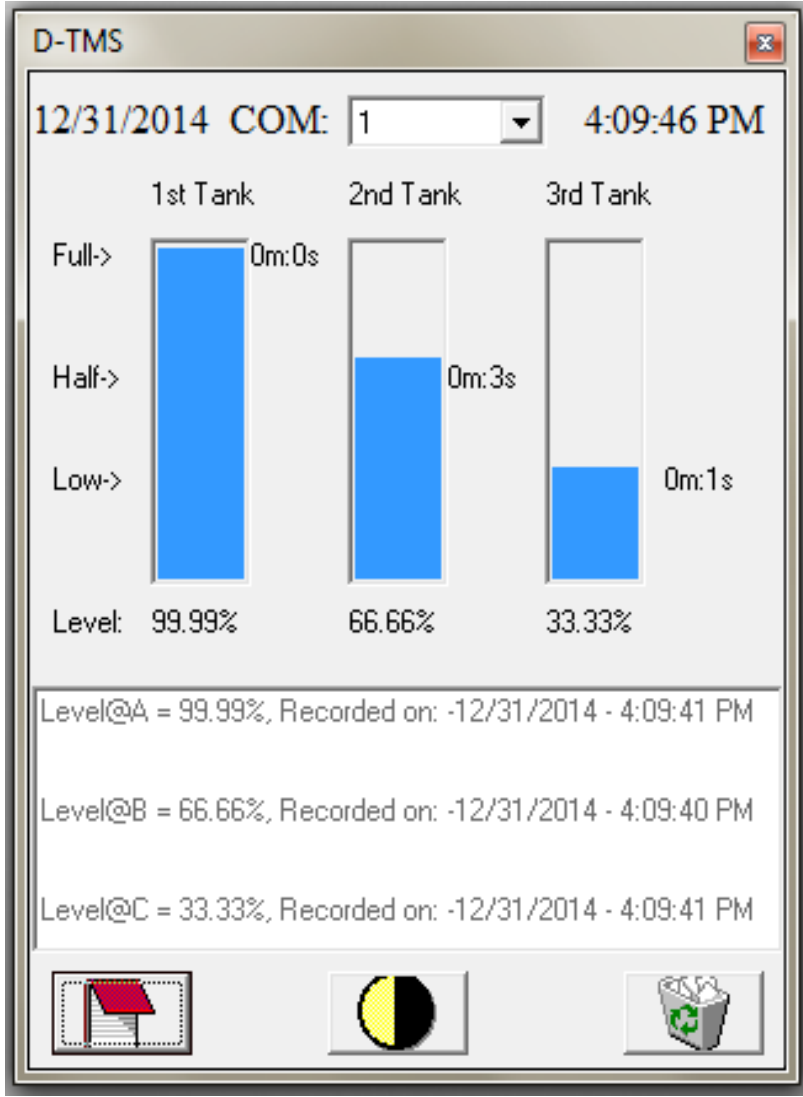

Figure 5: Software Designed For System in Visual Basic

In this the red icon shows the last recorded measurements history with date and time, on the right side there is delete $\operatorname{logs}$ button which require username and password to delete the logs and this is mainly for security purpose and only admin of the system will have right to delete logs, port will be selected from the scroll bar at the top, date and time are automatically taken by the software of the system at the time of measurements taken from the system.

\section{SYSTEM ENVIRONMENT}

System Environment is the work area in which system exist. It is of two types:

1. Hardware requirements

2. Software requirements

\section{1) Hardware Requirements}

1. MAX-232 chip.

2. RS-232 interface.

3. AT89S52 processing chip.

4. $434 \mathrm{MHZ}$ Radio sending module.

5. $434 \mathrm{MHZ}$ Radio receiving module

6. HT12E Encoder Chip

7. HT12D Decoder Chip

8. Alcoholic Thermometer

9. Pentium 4 processor

10. 1 GB RAM

11. $40 \mathrm{~GB}$ HDD

\section{2) Software Requirements}

Software is designed by using visual basic 6 for automatic control \& display with other features. In this system, a host software is working at a computer system which is equipped with hi-tech autonomous and intelligent features like autotime capture, auto-saving date and time, status of a particular level of particular tank in a file maintained on hard disk to hold this all data which it updates timely whenever it receives data.

Software is also equipped with the authentication process. If any one wants to delete the saved data, then he/she has to face the authentication process by entering the username and password. Artificial neural networks and fuzzy logic is also used for recognising codes.

\section{MEASUREMENTS OF OIL}

In Analysis Part of the system the measurements of the oil in the oil tanks are analysed during different temperature conditions i.e. how much the level of the oil in each particular oil tank varies or not.

\section{- $\quad$ Temperature Effects}

The most important factor in finding out the accuracy of oil is temperature i.e. to find out the accurate level in different temperature effects for e.g.:

1. When the temperature is too hot the consistency of the oil at that time becomes thin, at that time we will find the accuracy of each particular tank and also record the time taken by each tank to be filled.

2. When the temperature is too cold the consistency of the oil at that time becomes little harder as compare to the hot environment time, and then we will check the accuracy of the system with time taken by each particular tank.

3. Similarly, when the temperature effect is normal (not so hot or not so cold) then we will also check the accuracy of the oil with time taken by each particular tank to be filled.

\section{EXPERIMENTAL RESULTS}

In this phase, System is tested with different temperature conditions. We place the system in a cabin and by heating the room with heater we can provide the hot temperature (according to the quarterly average temperature values of a year which are considered from website www.accuweather.com) to the system. Similarly, by placing the system in A.C room we can provide cold temperature to the system and take the values of oil level. We measure the temperature with alcoholic thermometer.

The accuracy of oil in different temperature conditions over a year is explained as below:

We take the quarterly average temperature values from the website www.accuweather.com which is the American website and provides the accurate temperature values and we test the system. Here, TEMPERATURE, LEVEL and ACTUAL LEVEL are the three basic Parameters of the system. In which LEVEL shows the Level of oil displayed by the progress bars on the computer screen. ACTUAL LEVEL shows the actual level of oil in the oil tank. TEMPERATURE is the environment condition (hot, cold, normal) which change during the year. 


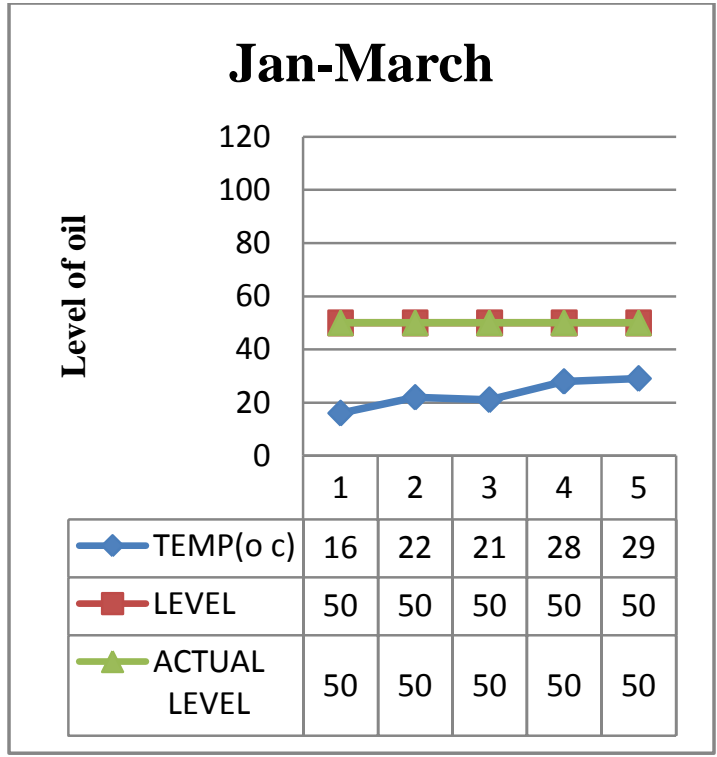

Graph 1: Shows no variations in level of oil

In graph 1 we consider the average temperature values of three months Jan, Feb and March. The Temperature is less then $30^{\circ} \mathrm{c}$ and there is no change in the Actual level of oil it is same as the Level shown by progress bars on the computer screen.

Similarly, In graph 2 as the month changes April, June, July the temperature will also increases from $30^{\circ} \mathrm{c}$, When the temperature raises after $30^{\circ} \mathrm{c}$ the level shown by progress bars on the computer screen will not same as the Actual level of tank. At that time Error has been detected there, i.e. the tank is having some empty space in it. This is because when the temperature increases after $30^{\circ} \mathrm{cthe}$ environment becomes hot and the consistency of the oil increases and, oil touches the sensing probes by expanding itself. The tanks have more space to add more oil in them.

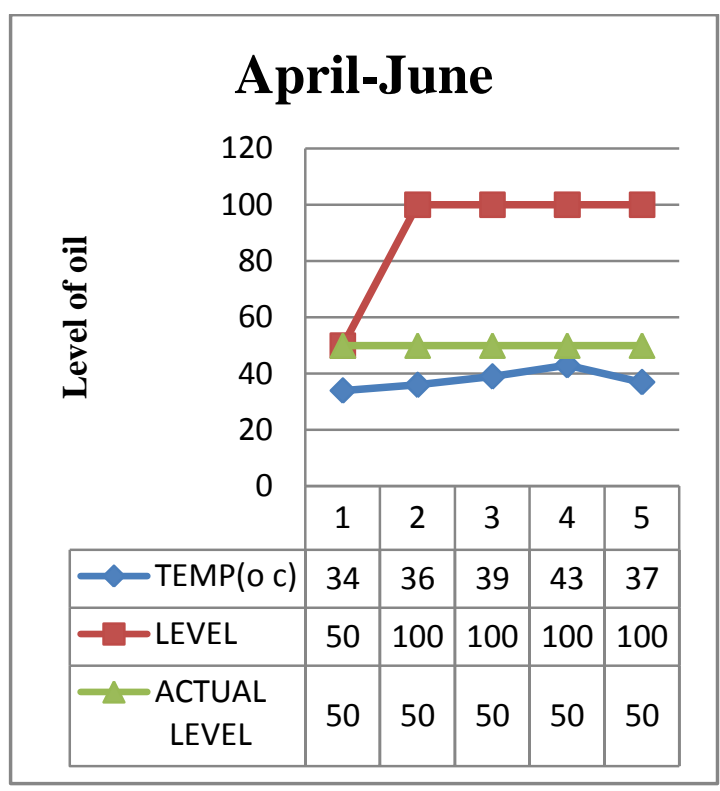

Graph 2: Shows variations in level of oil

In graph 3 July, August, September months are considered and temperature is greater then $30^{\circ} \mathrm{c}$, When the temperature raises after $30^{\circ} \mathrm{c}$ the level shown by progress bars on the computer screen will not same as the Actual level of tank. At that time Error has been detected there, i.e. the tank is having some empty space in it.

This is because when the temperature increases after $30^{\circ} \mathrm{c}$ the environment becomes hot and the consistency of the oil increases and, oil touches the sensing probes by expanding itself. The tanks have more space to add more oil in them.

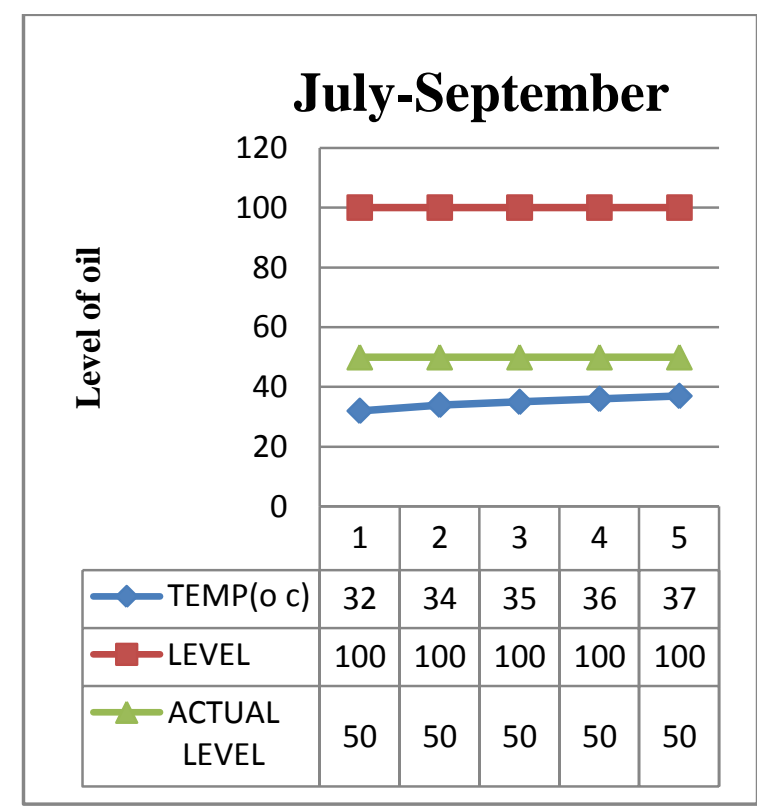

Graph 3: Shows variations in the level of oil

In graph 4 October, November and December months are considered and the Temperature is less then $30^{\circ} \mathrm{c}$ and there is no change in the Actual level of oil it is same as the Level shown by progress bars on the computer screen.

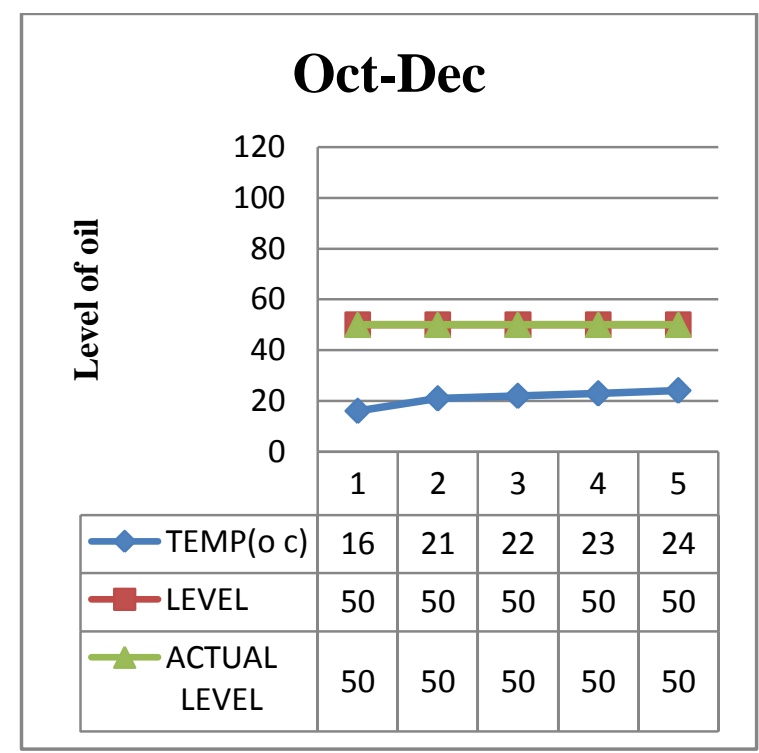

Graph 4: Shows no variations in level of oil

\section{CONCLUSION AND FUTURE WORKS}

In this Paper, Sensor Network Based Oil Monitoring System is presented by using demo design of the system for measuring the accurate measurements of oil in the given three oil tanks during different temperature conditions. In this system level of oil in each tank is displayed on the computer screen in the form of progress bars. 
In $1^{\text {st }}$ and $4^{\text {th }}$ quarter of the year the temperature is less then $30^{\circ} \mathrm{c}$ and there will be no effects on the measurements of oil in each tank. The progress bars show the ACTUAL LEVEL of oil in each particular tank.

In $2^{\text {nd }}$ and $3^{\text {rd }}$ quarter of the year as the temperature increases after $30^{\circ} \mathrm{c}$ the progress bars on the computer screen does not shows the ACTUAL LEVEL of oil, at this point error detection has been done i.e. The LEVEL shown by Progress bars is not same as the ACTUAL LEVEL of oil because when the temperature increases after $30^{\circ} \mathrm{c}$ environment becomes hot and the consistency of the oil expands. Due to increase in consistency of oil, oil touches the sensing probes by expanding itself and progress bars shows that the tanks are full and there is no space to add more oil in tank but actually there will be space in tanks to add more oil in them.

For Further Enhancements in the current design the Error which has been detected in the $2^{\text {nd }}$ and $3^{\text {rd }}$ quarter will be removed by working on the sensors or it may be removed by adding more nodes in neural network of the system to sense the ACTUAL LEVEL of oil and display the LEVEL same as ACTUAL LEVEL when the temperature raises after $30^{\circ} \mathrm{c}$ by sensing the inner and outer temperature of the system.

\section{ACKNOWLEDGEMENT}

We are extremely grateful and remain indebted to all the people who gave their support throughout the course of this work and a special acknowledgement to the authors of various research papers and books who gave us a lot of support.

\section{REFERENCES}

[1] Andy Trent, "Remote Telemetry System for Particulate Monitoring," United States Department of Agriculture Forest Service, 2002.

[2] Agoston, N. Dorr and B. Jakoby, 2006, -Online Application of sensors monitoring lubricating oil properties in biogas engines,\| IEEE Sensors 2006, EXCO, Daegu, Korea, October 22 - 25, 2006.

[3] A. H.El-Hag, Y.A.Saker, and I. Y. Shurrab, 2011, -Online oil condition monitoring using a partialdischarge Signal,\| IEEE Transactions on Power Delivery, Vol. 26, No. 2, April 2011.

[4] D. G. Senesky, B. Jamshidi, K. Cheng, and A. P. Pisano, "Harsh environment silicon carbide sensors for health and performance monitoring of aerospace systems: A review," IEEE Sensors J., vol. 9, no. 11, pp. 1472-1478, Nov. 2009.

[5] Donglin Wang, Member IEEE, Renlun He, Jiangqiu Han, Michel Fattoucho and Fadhel M. Ghonnouchi, Fellow, IEEE, "Sensor Network based Oil well Health Monitoring and Intelligent Control", IEEE Sensors Journal, vol 12, No. 5, May 2012.

[6] D. Pompili, T. Melodia, and I. F. Akyildiz.A Resilient Routing Algorithm for Long-term Applications in Underwater Sensor Networks. In Proc. of Mediterranean Ad Hoc Networking Workshop (Med-Hoc-Net). Lipari, Italy, Jun. 2006.

[7] E.E. Isaacs, H. Huang, A.J. Babchin and R.S. Chow,
1990, -Electroacoustic method for monitoring the coalescence of water-in-oil emulsions, $\|$ Colloids and surfaces, Vol. 46, pp. 177 - 192.

[8] I. Vasilescu, K. Kotay, D. Rus, M. Dunbabin , and P. Corke. Data Collection, Storage, and Retrieval with an Underwater Sensor Network . In ACM Conference on Embedded Networked Sensor Systems (SenSys ). San Diego, CA, Nov. 2005.

[9] Jakoby, M. Scherer, M. Buskies and H. Eisenschmid, 2003, - An automotive engine oil viscosity sensor,l IEEE Sensors. J, Vol. 3, pp. $562-568$.

[10] Jakoby and M.J. Vellekoop, 2004, —Physical sensors for water-in-oil emulsions, $\|$ Sensors and Actuators A, Vol. 110 , pp. $28-32$.

[11] Jennifer Yick, Biswanath Mukherjee, DipakGhosal, "Wireless sensor network survey" ,ELSEVIER Computer Networks 52 (2008) 2292-2330.

[12] Khalid EL-Darymli, Faisal Khan,Mohamed H. Ahmed. "Reliability Modeling of Wireless Sensor Network for Oil and Gas Pipelines Monitoring", Sensor \& Transducers Journal, Vol.106, Issue 7, July 2009, pp. 626, ISSN 1726-5479.

[13] K. Durdag, 2008, - Solid state acoustic wave sensors for realtimein line measurement of oil viscosity, Sensor Review, Vol. 28/1, pp.68 - 73.

[14] Musteric, "The Advanced Subminiature Telemetry System (ASMT): A Wireless, Non-Intrusive, Network Based, Instrumentation System," 2007 Test Instrumentation Workshop, Ridgecrest, CA, May 2007.

[15] M.Jain., S. Schmidt and C. Grimes, 2001, -Magneto Acoustic Sensors for Measurement of Liquid Temperature, Viscosity and Density,\| Applied Acoustic, 2001, Vol. 62, pp. $1001-1011$.

[16] Mohammad reza Akhondi, Alex, Simon Carlsen, Stig Petersen, "Applications of Wireless Sensor Networks in the Oil, Gas and Resources Industries", 24th IEEE International Conference on Advanced Information Networking and Applications, 2010.

[17] P. Xie and J.-H. Cui. SDRT: A Reliable Data Transport Protocol for Underwater Sensor Networks. University of Connecticut, Technical Report UbiNet-TR06-03, Feb. 2006.

[18] Q. He, G. Chen, X. Chen, X. Chen and C. Yao, 2009, -Application of oil analysis to the condition monitoring of large engineering machinery,\| IEEE 8th Conference on ICRMS, July 20 - 24, 2009.

[19] R. E. Kauffman and J.D. Wolf, 2001, -Development of onboard sensors for monitoring diesel engine oil condition,\| TACOM - TARDEC Final Report, Warren, MI, March

[20] Wu, D., Karray,F., Song ,I., "Water Level Control by Fuzzy Logic and Neural Networks," IEEE Conference on Control Applications, 2005 